\title{
Chronic Kidney Disease, A Herculean Task: Are There Effective Means Of Engagement In Alleviating The Burden?
}

\author{
Madhusudan Vijayan ${ }^{1}$, Rajalakshmi Ravi ${ }^{2}$, Georgi Abraham ${ }^{*}, 2,3$, Rama Ravi ${ }^{2}$ and Milli Mathew ${ }^{2,3}$ \\ ${ }^{I}$ Kilpauk Medical College, Chennai, India; Madras Medical Mission, Chennai, India \\ ${ }^{2}$ TANKER Foundation, Chennai, India \\ ${ }^{3}$ Pondicherry Institute of Medical Sciences, Pondicherry, India
}

\begin{abstract}
Non-communicable diseases are on the rise in India, of which chronic kidney disease (CKD) forms a considerable part. Little is known about CKD in India. The CKD registry of India submitted its first report in 2012 attempting to decipher the load of CKD. Only the tip of the iceberg has been explored, because this registry is the data collection from 200 odd nephrologists to whom these patients were referred, which is hospital based. The burden of CKD is felt to be immense and presumed to catapult in the forthcoming years. The available facilities for renal replacement therapy are sparse, confined to urban areas and certain regions of the country. There is an imminent need for focusing on preventive aspect including screening practices and educational measures to alleviate the burden of CKD. Screening of high risk groups with urine dipstick test and serum creatinine estimation and estimated glomerular filtration rate (eGFR) based on this, is currently recommended by international experts, although debate exists as to whether to screen the entire population or only susceptible and older individuals. Educational interventions aimed at creating awareness are warranted owing to the current circumstances. The Government has to put in place decisive measures to control and monitor the disease. Public private partnerships could play a major role in the future. For the control of CKD as a whole in India, participation from professionals industry, philanthropic organizations with active involvement of Government is necessary.
\end{abstract}

Keywords: CKD, education, engagement, India, screening.

\section{INTRODUCTION}

The burden of Chronic Kidney Disease (CKD) in India is beginning to be unraveled. Since India is a pluralistic country in terms of socioeconomic status, cultural and religious practices, cuisine and ethnicity, it requires an extensive study to address management strategies due to the enormous burden faced by the medical professionals in India. The Indian CKD registry was set up in 2005 by the Indian Society of Nephrology with the aim of studying the distribution and determinants of CKD in India.

The CKD registry submitted its first report in 2012 [1], after analyzing 52273 adult patients and 1818 pediatric patients, from 188 contributing centers across the country. The mean age was $50.1 \pm 14.6$ years, with a male to female ratio of 70:30. Diabetic nephropathy was the commonest cause $(31 \%)$, followed by CKD of undetermined etiology $(16 \%)$, chronic glomerulonephritis (14\%) and hypertensive nephrosclerosis (13\%). The underprivileged patients who presented at government hospitals were younger and more likely to present at Stage V with undetermined etiology. Diabetes was equally prevalent in CKD patients attending public and private hospitals. The CKD registry of India

*Address correspondence to this author at the Madras Medical Mission Hospital, 4A, Dr. J. Jayalalitha Nagar, Mogappair, Chennai 600037, India; Tel: 91 9841710992; Fax: 91-44-26565859;

E-mail: abraham_georgi@yahoo.com report represents only the tip of the iceberg, because the data was availed only through nephrologists and is hospitalbased. The vast majority of patients in the earlier stages of $\mathrm{CKD}$ and those who do no avail treatment do not feature in the registry.

The Screening and Early Evaluation of Kidney Disease (SEEK) study analyzed 5588 people in 12 Indian cities and estimated the prevalence of CKD in India at 17.2\% [2].

An ongoing prospective screening program by TANKER foundation in Tamil Nadu, involving individuals in temples, churches, factories, offices and other institutions showed a proteinuria of $1+$ or more in dipstick in $19.86 \%$ of individuals, till now [3].

The epidemic of diabetes, improved life expectancy and an ageing population in the future can be expected to contribute to the surging incidence of CKD in the near future. As it is, the existing renal replacement therapy services are meager. Hence India has a long way to go in the control of CKD.

\section{COMPARISON WITH OTHER COUNTRIES}

Reports from other countries participating in the Global SEEK project have been published. The results of SEEKThailand study using a cluster randomized design showed $17.5 \%$ prevalence of CKD [4]. The SEEK-Saudi Arabia showed a prevalence of 5.7\% [5]. The United States Renal 
Data System (USRDS) places the prevalence of CKD at $14 \%$ among the general population [6]. Around 1 in 10 Australians above 18 years have indicators of CKD such as proteinuria and/or reduced GFR [7]. About 13\% of Japanese adults had CKD, according to a 2005 study [8]. In Taiwan, the prevalence of CKD is reported to be $6.9 \%$ for CKD stage $3-5,9.83 \%$ for clinically recognized CKD and $11.9 \%$ for CKD stage 1-5 [9]. A pilot study in Nepal reported 10.6\% prevalence [10]. Thus the prevalence of CKD in India is quite higher compared to other countries.

\section{HEALTHCARE IN INDIA}

Health care spending in India as proportion of gross domestic product (GDP) is among the lowest in the world. While the United States spends $17.9 \%$ of GDP in healthcare, and the United kingdom spends $9.3 \%$, India spends merely $3.9 \%$, according to World Bank estimates [11]. The Indian healthcare expenditure has grown slower than the economy, unlike most other developing economies.

India has a universal public health care delivery system, which caters mainly to the poorer sections of the society. The public health system provides subsidized treatment to the patients, and aims to control diseases through implementation of national health programmes. The rural population is served by primary health centres with utmost basic facilities. The nephrology force in India is 1 per 1.1 million population, which is unevenly distributed across different states and urban and rural areas. The rural population also relies on alternative forms of treatment including ayurveda, unani and acupuncture.
The private health care facilities that thrive in urban centres are fairly adequate and cater to the affluent sections. Ironically the private health sector in India is felt to be cheap in comparison to international standards and is availed by medical tourists from across the globe.

Public private collaboration has not yet risen to the desired extent. There is an evident inter-state disparity in the quality and quantity of healthcare, with Southern and Western states scoring better [12].

India currently has close to 1100 nephrologists all over the country. An article published in 2009 by Agarwal and Srivastava highlights that only $10 \%$ of new End Stage Renal Disease (ESRD) patients start on RRT [13, 14]. However the great majority of these patients do not continue on RRT as this modality is unaffordable [15]. The bulk of the renal replacement therapy (RRT) in India is handled by the private sector [14]. The Government of India does not have national programmes to support haemodialysis in India. The government has launched National Organ Transplant Program (NOTP) to facilitate both living and cadaver transplantation [14]. Nevertheless the facilities for RRT in India are dreadfully inadequate and beyond the spending capacity of the majority of the population.

The Government of India is planning to set up standalone dialysis units in partnership with private centers [14]. Various state governments such as Kerala (Karunya scheme [16]) and Andhra Pradesh (Arogyarasi scheme [17]) have already set up schemes to provide free dialysis to patients in public hospitals. Tamil Nadu Government program for dialysis and transplantation through government funding is benefitting many below the poverty line through recognized medical centers.

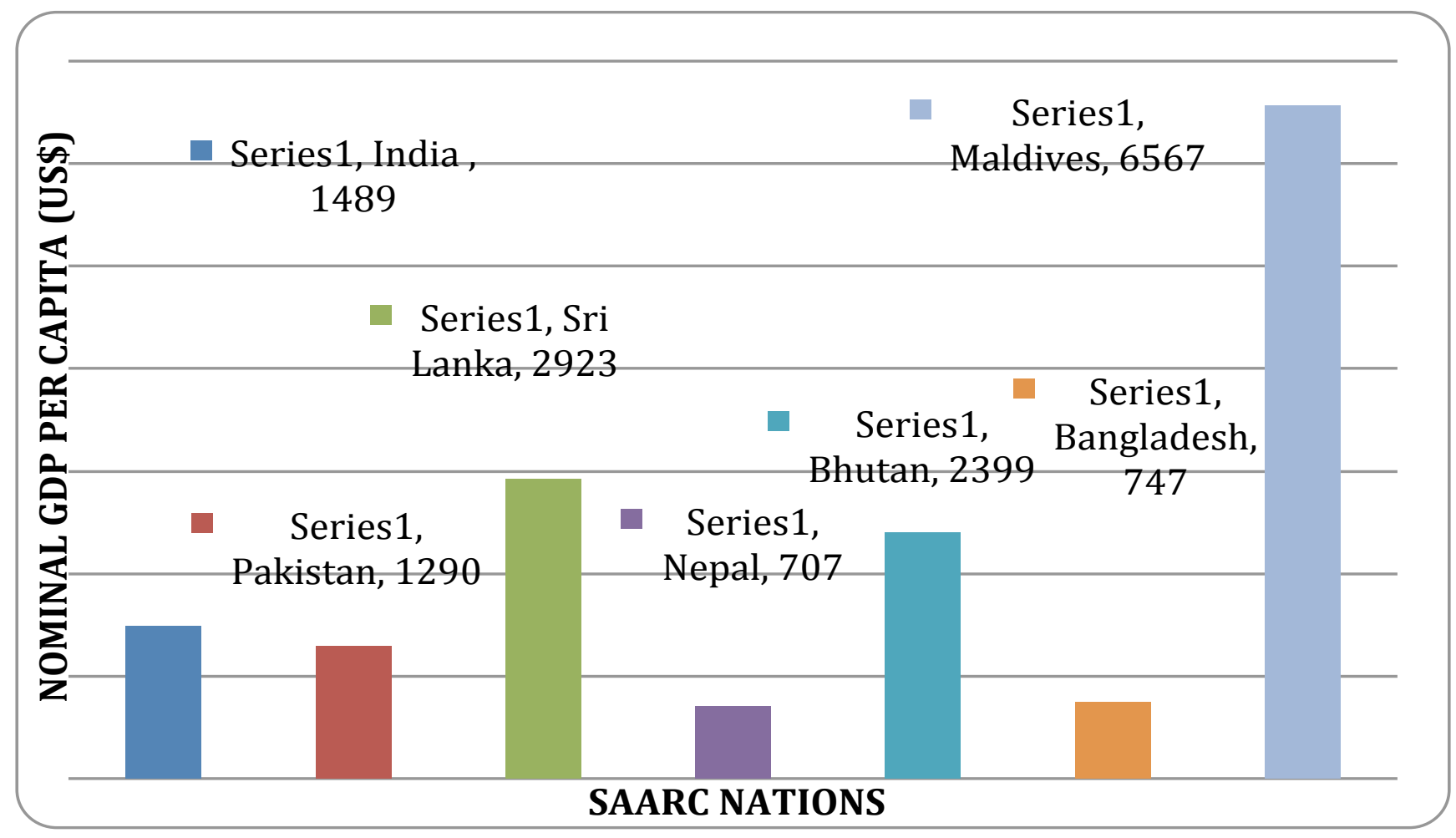

Fig. (1). Nominal GDP per capita (US\$) of SAARC nations, data from world bank development indicators. 
It is reasonable to assume that the situation is comparable to that prevalent in various other South Asian Association for Regional Cooperation (SAARC) nations as well. Fig. (1) shows the nominal Gross Domestic Product (GDP) per capita of the SAARC countries [11].

A recent article highlights that RRT has an uncertain economic future in USA, owing to astronomic federal debt and unfunded liability burden of Medicare [20]. Compared to USA, the cost of RRT in India is extremely cheap, yet unaffordable to many.

\section{HOW TO TACKLE THIS HERCULEAN TASK}

With a rising CKD population and limited RRT facilities, the focus is on prevention, primordial, primary and secondary. Primordial prevention aims to control the occurrence of risk factors for CKD, including diabetes and hypertension, through educational interventions. Primary prevention has special focus on high risk groups such as those with diabetes mellitus, hypertension, family history of kidney disease and those who engage in alternative medicine therapy which is unsupervised. Secondary prevention is of utmost importance and is achieved through screening.

\section{SCREENING}

Since various studies have shown that the prevalence of $\mathrm{CKD}$ in India is quite high and steadily rising, the healthcare costs will rise and the facilities for RRT for the affected people will be inadequate. In order to circumvent this, detection of the disease in its early stages is important in order to arrest the progression of the disease. Thus the need to screen people for CKD arises.

\section{WHOM TO SCREEN}

So do we screen the whole population for CKD? A study [18] done in USA shows that screening for proteinuria has an unfavourable cost effectiveness ratio (282 818 dollars per QALY; incremental cost of 616 dollars and a gain of 0.0022 QALYs per person). The applicability of this finding to India is questionable because the etiological risk factors between the 2 countries differ.

However the study shows that it is cost effective if the screening is targeted at the aforementioned high risk groups. The general consensus among experts from around the world is that CKD screening should be carried out among high-risk groups, including diabetes, hypertension and cardiovascular disease [17].

\section{HOW TO SCREEN}

The KDIGO conference in Amsterdam 2006 suggests including a urine test for protein and a serum test for creatinine to estimate GFR [19]. Tests for proteinuria should be selected and performed according to local guidelines. Verification of proteinuria would require two out of three positive tests. Equations for estimating GFR should be appropriate for standardization of the method and application to majority racial and ethnic groups. Compared to cardiovascular screening including ECG and echocardiogram, and gastrointestinal screening of endoscopy or CT scan, and bronchoscopy, or CT or MRI brain, the CKD screening involves much lesser costs (Less than Rs 100/- per person per time).

\section{WHEN TO SCREEN}

Studies show that when targeted at high-risk groups, annual screening is cost effective [19]. However screening persons aged 50 years or older with neither hypertension nor diabetes at a frequency of every ten years approached favorable cost effectiveness ratios, compared to annual screening [19]. As the life expectancy in India is 65.48 years as of 2011, it may be worth starting the screening just above 40 years of age.

\section{WHO SHOULD SCREEN}

Since screening for CKD is not an invasive or skilled procedure, it does not require highly trained professionals. Personnel trained in simple patient assessment including blood pressure checking, urine examination using dipstick and collecting sample for blood work can easily perform the required investigations in CKD screening.

\section{EDUCATION, A POWERFUL YET UNDER- UTILIZED TOOL}

Carl Rogers said, "The only person who is educated is the one who has learned how to learn and change." Effective education is based on effective communication. Communication is not merely exchange of information. It paves the way for desired changes in human behavior to achieve predetermined goals. By preparing the people with roles expected of them, we can launch a powerful campaign against $\mathrm{CKD}$ in India.

Education should reach the masses, especially the high risk groups for CKD. This could be done through visual and print media, direct confrontation. They should be fully informed of the nature, extent, progression, preventive and therapeutic aspect of the disease. This is the mode of approach adopted by TANKER foundation (ww.tankerfoundation.org) for the last decade.

Education also encompasses the increasing the pool of nephrologists in the country. The number of nephrology seats in Indian medical colleges is woefully less [14]. There are only $88+$ seats per year for courses lasting for 3 years, after which the qualifying nephrologists can provide RRT. Steps to increase and improve nephrology education are recommended.

\section{ENGAGEMENT WITH OTHER WALKS OF LIFE}

The Government is yet to give the deserving importance to $\mathrm{CKD}$ as a public health problem in India, despite the alarming numbers. Comprehensive strategies are required to ensure early detection, improved renal replacement therapy services, appropriate referral system and intensive monitoring and surveillance.

Since working together reaps success in leaps and bounds, engagement with people from other walks of life can produce desirable results in the control of CKD. Indians have 
a strong belief in religious establishments such as temples, churches, mosques and gurudwaras, where they offer weekly/daily prayers. These establishments are a platform for screening of people, and promoting public awareness about the epidemic of CKD.

Public Private Partnership (PPP) is crucial in tackling the CKD health menace, since this can ensure universalized renal replacement therapy to the masses. The poor people tend to present at stage $\mathrm{V}$, where the need for RRT becomes imminent. However at present, RRT is better used by the affluent sections, and hence PPP becomes essential to provide RRT for the poorer socioeconomic classes.

Various multinational companies (MNC) could spend a portion of their profit in public health awareness and screening. For the control of the CKD epidemic in India, a population strategy is mandatory. Everybody should be a partner in the screening, early diagnosis and follow-up of CKD patients.

\section{CONFLICT OF INTEREST}

The authors confirm that this article content has no conflict of interest.

\section{ACKNOWLEDGEMENTS}

Declared none.

\section{REFERENCES}

[1] Rajapurkar MM, John GT, Kirpalani AL, et al. What do we know about chronic kidney disease in India: first report of the Indian CKD registry. BMC Nephrol 2012; 13:10.

[2] Singh AK, Farag YMK, Mittal BV, et al. Epidemiology and risk factors of chronic kidney disease in India- results from the SEEK (Screening and early evaluation of kidney disease) study. BMC Nephrol 2013; 14:114.

[3] Ravi R, Ravi R, Pandian D, et al. Awareness and screening as a tool to detect and prevent early kidney disease-A model for developing countries. Paper presented at: World Congress of Nephrology: May 31 June 4, Hong Kong 2013.

[4] Ingsathit A, Thakkinstian A, Chaiprasert A, et al.: Prevalence and risk factors of chronic kidney disease in the thai adult population: Thai SEEK study. Nephrol Dial Transplant 2010, 25(5):1567-75.

[5] Alsuwaida AO, Farag YM, Al Sayyari AA, et al.: Epidemiology of chronic kidney disease in the kingdom of saudiarabia (SEEK-saudi investigators) - a pilot study. Saudi J Kidney Dis Transpl 2010, 21(6):1066-72.

[6] U.S. Renal Data System, USRDS 2012 annual data report: atlas of chronic kidney disease and end-stage renal disease in the United States, national institutes of health, national institute of diabetes and digestive and kidney diseases. Bethesda, MD 2012.

[7] Fast facts on CKD in Australia. Kidney Disease Australia. Last updated August 2013. Accessible from: http://www.kidney.org.au/ Kidney Disease/Fast Factson CKD in Australia/ tabid/589/Default. aspx

[8] Imai E, Horio M, Watanabe T, et al. Prevalence of chronic kidney disease in the Japanese general population. Clin Exp Nephrol 2009; 13(6): 621:30.

[9] Hwang SJ, Tsai JC, Chen HC. Epidemiology, impact and preventive care of chronic kidney disease in Taiwan. Nephrology (Carlton) 2010; 15(2): 3-9.

[10] Sharma SK, Dhakal S, Thapa L, et al. Community-based screening for chronic kidney disease, hypertension and diabetes in Dharan. J Nepal Med Assoc 2013; 52(189): 205-12.

[11] World Development Indicators Database. Updated on August 1, 2013. Accessed on August 8, 2013. Accessible from: http://databank.worldbank.org/data/home.aspx

[12] Southern, Western states keep India healthy, Azad says. Times India 2012; 8: 22.

[13] Khanna U. The Economics of dialysis in India. Indian J Nephrol 2009; 19(1): 1-4

[14] Agarwal SK, Srivastava RK. Chronic kidney disease in India: challenges and solutions. Nephron Clin Pract 2009; 111: c197-203.

[15] Singh P, Bhandari M. Renal replacement therapy options from an Indian perspective: dialysis vs. transplantation. Transplant Proc 2004; 36 (7): 2013-4.

[16] Express News service. Government hospitals to get dialysis units under Karunya scheme. New Indian Express 2012; 10: 5.

[17] Staff Reporter. Towards Cheaper dialysis. Hindu 2011; 4:1.

[18] Bouleware LE, Jaar BG, Tarver-Carr ME, Brancati FL, Powe NR Screening for proteinuria in USA adults: A cost-effective analysis. JAMA 2003; 290: 3101-14.

[19] Powe NR, Bouleware LE. Population-Based Screening for CKD. Am J Kidney Disease 2009; 53 (3 Suppl 3): S64-70.

[20] Anderson MJ, Friedman AN. The coming fiscal crisis: nephrology in the line of fire. Clin J Am Soc Nephrol 2013; 8: 1252-7. 